\title{
Elongation of the Kcnq1ot1 transcript is required for genomic imprinting of neighboring genes
}

\author{
Debora Mancini-DiNardo, Scott J.S. Steele, John M. Levorse, Robert S. Ingram, \\ and Shirley M. Tilghman ${ }^{1}$ \\ Department of Molecular Biology, Princeton University, Princeton, New Jersey 08544, USA
}

\begin{abstract}
The imprinted gene cluster at the telomeric end of mouse chromosome 7 contains a differentially methylated CpG island, KvDMR, that is required for the imprinting of multiple genes, including the genes encoding the maternally expressed placental-specific transcription factor ASCL2, the cyclin-dependent kinase CDKN1C, and the potassium channel KCNQ1. The KvDMR, which maps within intron 10 of Kcnq1, contains the promoter for a paternally expressed, noncoding, antisense transcript, Kcnq1ot1. A 244-base-pair deletion of the promoter on the paternal allele leads to the derepression of all silent genes tested. To distinguish between the loss of silencing as the consequence of the absence of transcription or the transcript itself, we prematurely truncated the Kcnq1ot1 transcript by inserting a transcriptional stop signal downstream of the promoter. We show that the lack of a full-length Kcnq1ot1 transcript on the paternal chromosome leads to the expression of genes that are normally paternally repressed. Finally, we demonstrate that five highly conserved repeats residing at the $5^{\prime}$ end of the Kcnq1ot1 transcript are not required for imprinting at this locus.
\end{abstract}

[Keywords: Genomic imprinting; Kcnq1ot1; DNA methylation; noncoding RNA; RNA-dependent silencing]

Received February 2, 2006; revised version accepted March 17, 2006.

Mammalian development requires the genetic contribution of both parental genomes (McGrath and Solter 1984; Surani et al. 1984). This requirement can be accounted for by the existence of $\sim 80$ imprinted genes whose expression is monoallelic based on the parent of origin (http://www.mgu.har.mrc.ac.uk/research/imprinting/ imprin-viewdata.html). The precise mechanisms governing genomic imprinting are not fully understood, yet the propensity of imprinted genes to exist in clusters suggests that regulatory mechanisms that act over large genomic distances are likely to be involved. Indeed, studies of several imprinted chromosomal domains have identified imprinting control regions (ICRs) that coordinate the imprinting of multiple genes over hundreds of kilobases of DNA (Leighton et al. 1995; Wutz et al. 1997; Thorvaldson et al. 1998; Bielinska et al. 2000; Fitzpatrick et al. 2002; Lin et al. 2003).

The regulatory elements governing the imprinting of the genes at the distal end of mouse chromosome 7 have been the subject of extensive investigation (Fig. 1A). The more centromeric H19, Igf2, and Ins2 genes are coordinately regulated by a single ICR located 5' of H19 (Leighton et al. 1995; Thorvaldson et al. 1998). On the maternal

${ }^{1}$ Corresponding author.

E-MAIL smt@princeton.edu; FAX (609) 258-1615.

Article and publication are at http://www.genesdev.org/cgi/doi/10.1101/ gad.1416906. chromosome the ICR binds CTCF, a zinc-finger protein, which mediates the activity of an enhancer blocker that inhibits the access of enhancers $3^{\prime}$ of H19 to Igf2 and Ins2 (Bell and Felsenfeld 2000; Hark et al. 2000; Kaffer et al. 2000; Kanduri et al. 2000). On the paternal chromosome DNA methylation at the ICR, acquired during spermatogenesis, inhibits CTCF binding and spreads after fertilization to the H19 promoter to inhibit its expression. Deletion of the ICR eliminates imprinting of H19, Igf2, and Ins2, but has no effect on the imprinting of genes that lie telomeric to Ins2 (Leighton et al. 1995; Caspary et al. 1998; Thorvaldson et al. 1998).

The telomeric region contains at least eight maternally expressed genes that include Ascl2, which encodes an essential placenta-specific transcription factor (Guillemot et al. 1995), Cdkn1c, encoding a cyclin-dependent kinase inhibitor (Hatada and Mukai 1995), and Kcnq1, encoding a potassium channel (Gould and Pfeifer 1998). However, the extent of the imprinting of these genes is highly variable. For example, $C d k n 1 c$ is expressed exclusively from the maternal allele in all expressing tissues and at all stages of development, while Kcnq1 is imprinted early in embryogenesis in a variety of tissues but becomes fully biallelic in adult tissues (Caspary et al. 1998; Gould and Pfeifer 1998), and expression and imprinting of Ascl2 is restricted to the placenta (Guillemot et al. 1995).

The region also harbors a gene encoding a single pa- 
A

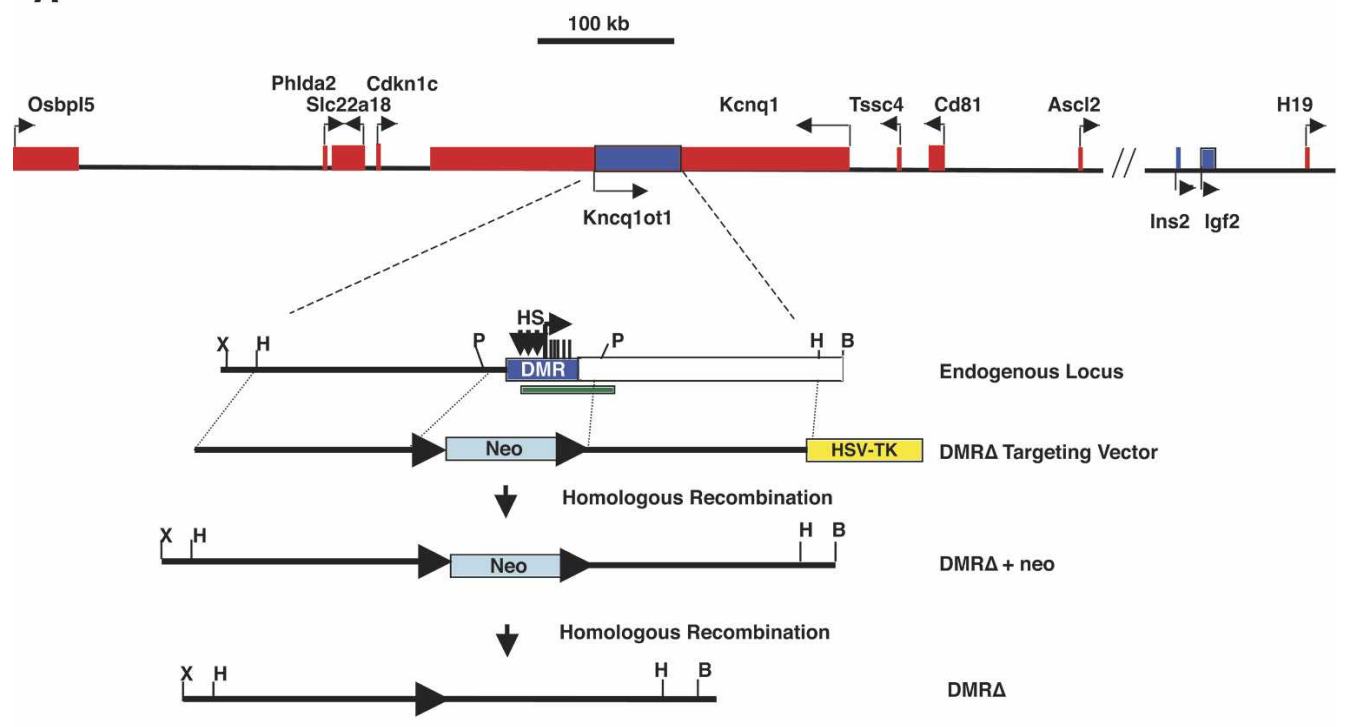

B
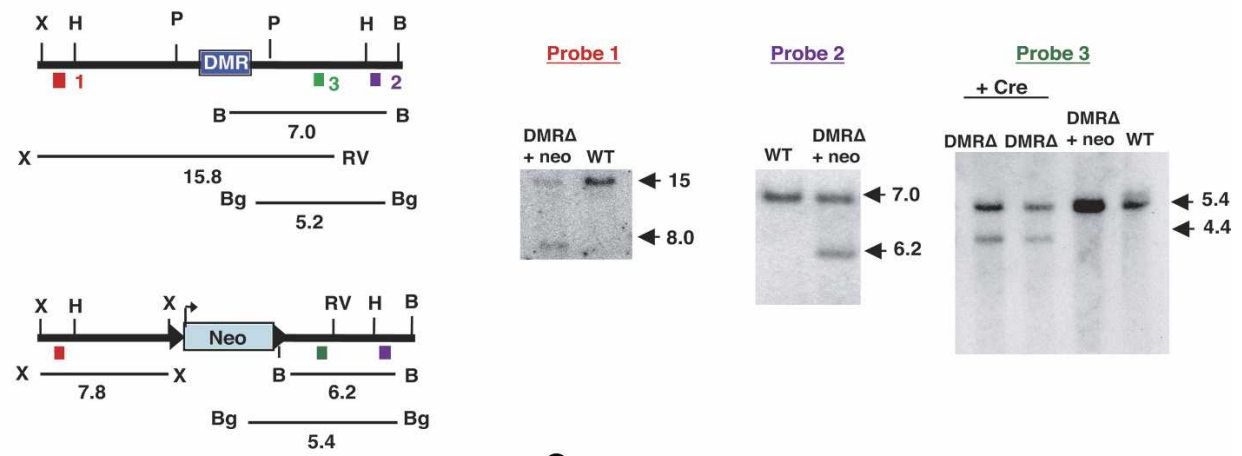

C
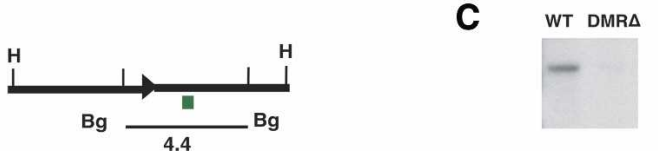

Figure 1. Deletion of the KvDMR. (A) The top line represents a physical map of the imprinted domain in mouse distal chromosome 7, with maternally expressed genes represented by red boxes and paternally expressed genes shown as blue boxes. Depicted below is an enlargement of the KvDMR (blue box), illustrating the three DNase I hypersensitivity sites (HS; vertical arrows), the Kcnq1ot1 transcription start site (horizontal arrow), and the five repeats (vertical bars). The location of the KvDMR deletion described by Fitzpatrick et al. (2002) is depicted by the green rectangle. The targeting vector is shown below, in which the neomycin resistance gene (neo) flanked by loxP sites (closed triangles) replaces $3.6 \mathrm{~kb}$ of the DMR. The herpes simplex virus thymidine kinase gene (HSV-TK) was included to provide negative selection. The structures of the targeted loci, before and after the deletion of the neo gene, are indicated. $(B)$ Southern blot analysis of DNAs prepared from wild-type (WT), heterozygous DMR $\Delta+$ neo, and heterozygous DMR $\Delta$ $(-n e o)$ mice after digestion with restriction enzymes and hybridization with the probes 1-3 as indicated in the diagrams. The diagrams of the endogenous and targeted loci depict the positions and sizes of the fragments detected by the probes. (C) RNA protection analysis of RNAs isolated from wild type and mice inheriting DMR $\Delta$ paternally using probe 3. (P) PstI; (X) XhoI; (H) HindIII; (B) BamHI; (RV) EcoRV; (Bg) BglI.

ternally expressed transcript, Kcnq1ot1, whose promoter is contained within intron 10 of the $320-\mathrm{kb}-$ long Kcnq1 gene (Smilinich et al. 1999). The $\sim 60-\mathrm{kb}$ transcript is unspliced and is transcribed in the direction opposite to that of Kcnq1. Its promoter lies within an extensive CpG island that is methylated selectively on the maternal chromosome (KvDMR) (Mancini-DiNardo et al. 2003). Paternal deletion of $2.8 \mathrm{~kb}$ of the KvDMR in the mouse germline demonstrated that it was required for the silencing of at least six neighboring genes on the paternal chromosome (Fitzpatrick et al. 2002).

From the outset it seemed unlikely that the mechanism of action of the KvDMR resembled that at the H19 ICR. Enhancer blockers are highly position dependent, in that they must reside between the gene and the enhancer to inhibit transcription. The complexity of the arrange- 
ment of the genes on both sides of the KvDMR and their varied expression patterns make an enhancer-blocking model difficult to orchestrate. Indeed using in vitro transfection assays, the KvDMR behaved as a silencer rather than as an enhancer blocker (Mancini-DiNardo et al. 2003; Thakur et al. 2003). The other well-established mechanism for silencing imprinted genes is the RNAdependent silencing by an antisense transcript, as occurs at the Igf2r locus in the mouse (Sleutels et al. 2002).

In this report, we show that silencing by the KvDMR requires transcription of $K \operatorname{cnq} q 10 t 1$, and it is either the transcript itself or its transcriptional elongation that is critical, not its initiation. We also test the possibility that five highly conserved repeat elements located at the 5' end of the Kcnq1ot1 transcript are required for silencing, as has been shown for similar repeats in the Xist noncoding transcript that are required for $\mathrm{X}$ chromosome inactivation (Wutz et al. 2002). In the case of Kcnq1ot1, the repeats are dispensible for silencing.

\section{Results}

\section{Deletion of the KVDMR}

Fitzpatrick et al. (2002) previously reported that a 2.8-kb deletion of the KvDMR leads to disruption of silencing of six genes located on both sides of the deletion. We have confirmed their result and refined the mapping of the KvDMR by using homologous recombination in embryonic stem (ES) cells to generate a $3.6-\mathrm{kb}$ deletion that includes an additional $1.7 \mathrm{~kb} 5^{\prime}$ to the first deletion, but leaves 875 base pairs (bp) 3' of the deletion intact (Fig. 1A). The region that is deleted contains the entire differentially methylated CpG island, three hypersensitive sites that coincide with the promoter of Kcnq1ot1, and five repeats that lie within the transcript itself. Correctly targeted ES cells were introduced into C57BL/6 blastocysts, and the resulting males were bred to C57BL/6 females to yield germline transmission of the mutation and the removal of the neomycin cassette (Fig. 1B). To confirm that the deletion eliminated expression of Kcnq1ot1 we examined its expression by a ribonuclease protection assay. After paternal inheritance of the $\mathrm{DMR} \Delta$, the noncoding Kcnq1ot1 transcript was not detected (Fig. 1C).

We tested the effect of the deletion on the imprinting of six maternally expressed genes by crossing $F_{1}$ mutant mice to congenic mice that harbor Mus spretus alleles of all genes on the distal end of chromosome 7. RNAs were prepared from embryos at embryonic day 13.5 (E13.5), a time in development when the imprinting of these genes is still intact, and allele-specific RT-PCR assays were used to assess the expression of the imprinted genes. Paternal transmission of the deletion led to biallelic expression of Ascl2, Kcnq1, Cdkn1c, Slc22a18, Phlda2, and Osbp15 (Fig. 2). For each PCR reaction, we conducted control experiments in which the two parental alleles were represented in ratios of $1: 1,3: 1$, and 1:3. For Kcnq1, Cdkn1c, Osbp15, and S1c22a18, there was a bias in favor of the M. spretus allele, and for Ascl2 there was a C57BL/ 6 bias. When these biases are taken into account,

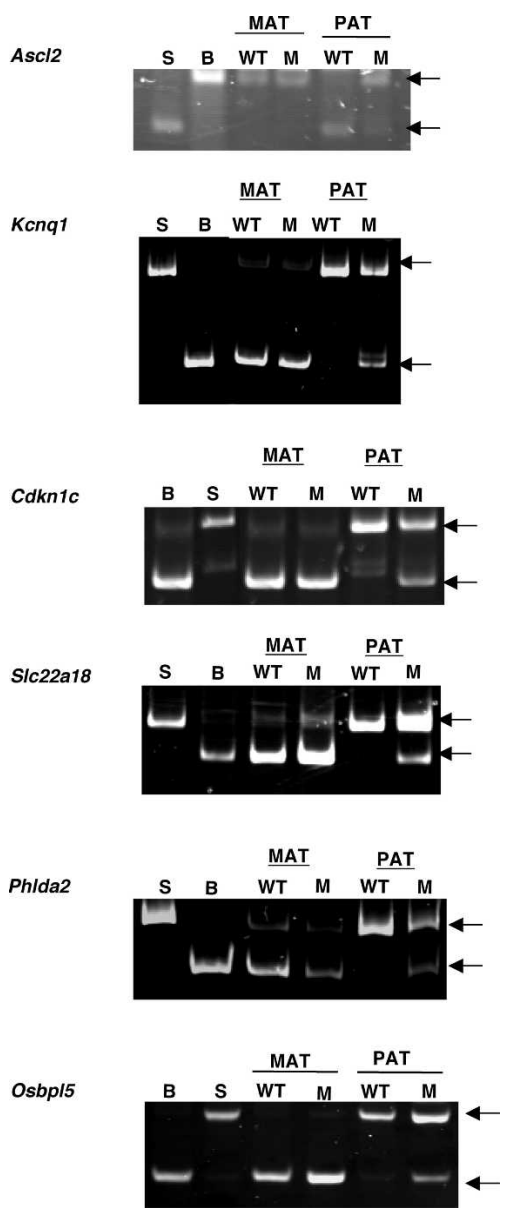

Figure 2. Effect of the KvDMR deletion on imprinting. Allelespecific RT-PCR assays were used to analyze the expression of the genes listed on the left using primers specific for each transcript (Table 2). Analysis was performed on E13.5 placental RNA isolated from offspring of reciprocal crosses between heterozygous DMR $\Delta$ and $M$. spretus mice $(\mathrm{M})$ as well as their wildtype littermates (WT). (MAT) DMR $\Delta \times M$. spretus; (PAT) $M$. spretus $\times \mathrm{DMR} \Delta_{\text {; }}$ (B) C57BL/6; (S) M. spretus. The arrows on the right refer to the allele-specific products.

the expression of the two parental alleles in the paternally inherited mutations is roughly equal.

In contrast, these genes displayed normal imprinted expression when the KvDMR deletion was inherited maternally. Our results confirm that the KvDMR functions as an ICR, and by showing that the most telomeric gene, Osbp15, falls under the influence of KvDMR, we significantly extend the size of the domain to at least $446 \mathrm{~kb}$ centromeric and $330 \mathrm{~kb}$ telomeric to KvDMR. We have also further delimited the essential sequences to 1.925 $\mathrm{kb}$ within the KvDMR. The deletion has no impact on the imprinting of Igf2, H19, and Ins2, which are regulated by a separate ICR (Fitzpatrick et al. 2002; data not shown).

We examined the effect of paternal inheritance of the DMR deletion on the growth of heterozygotes as compared with their wild-type littermates. We observed a $10 \%-20 \%$ decline in weight, consistent with the find- 
ings of Fitzpatrick et al. (2002). No other gross phenotypic changes were noted.

$D M R \Delta$ rescues lethality of a Cdkn1c loss of function mutant

The absence of $C d k n 1 c$ has been shown to affect the ability of cells to exit the cell cycle, and Cdkn1c null mice show a variety of phenotypes including renal dysplasia, lens and gastrointestinal abnormalities, and skeletal defects (Yan et al. 1997; Zhang et al. 1997). Approximately $10 \%$ of these mice die in utero, with the remainder dying within 2 wk of birth. Since the deletion of KvDMR results in expression of Cdkn1c from the normally silent paternal allele, we asked if the level of paternally provided CDKN1C in DMR $\Delta$ mice could rescue a $C d k n 1 c$ loss of function mutation. We crossed $C d k n 1 c$ mutant females with DMR $\Delta$ males and looked for $C d k n 1 c$ mutant progeny that lived beyond 2 wk of age. Of the animals that lived to adulthood we observed 10 Cdkn1c/DMRs double mutants, six wild type, six DMR $\Delta$ s, and, as expected, no Cdkn1c single mutants. Northern analysis confirmed wild-type levels of $C d k n 1 c$ mRNA in double-mutant animals (data not shown). These results demonstrate that the deletion of KvDMR results in expression of $C d k n 1 c$ from the paternal allele that is sufficient to rescue the $C d k n 1 c$ mutation, although it is formally possible that biallelic expression of other genes on the paternal allele may contribute to the survival of these mice.

\section{Deletion of the Kcnq1ot1 promoter}

We previously demonstrated that the promoter of the antisense transcript Kcnq1ot1 is contained with the KvDMR (Mancini-DiNardo et al. 2003). To test whether regulation of imprinting at this locus requires the transcription of Kcnq1ot1, we used homologous recombination in ES cells to generate a 244-bp deletion of the Kcnq1ot1 promoter (Fig. 3A). This deletion removes two of the three allele-specific DNase I hypersensitive sites within the promoter region and the transcription start site itself (Mancini-DiNardo et al. 2003), but leaves most of the CpG island intact. Once heterozygous mice containing the promoter deletion and missing the neomycin cassette were obtained (Fig. 3B,C), we used an RNase protection assay to ascertain whether paternal Kcnq1ot1 transcription was eliminated. Using a probe derived from $481 \mathrm{bp}$ downstream of the transcription start site, we show in Figure 3D that no transcript was detected when the deletion was inherited paternally.

We then tested the effect of the Kcnq1ot1 promoter deletion on the imprinting of seven maternally expressed genes using E11.5 embryos and placentae (Fig. 4). Paternal transmission of the Kcnq1ot1 promoter deletion activated the normally silent paternal alleles of all genes tested, while proper expression was maintained when the Kcnq1ot1 promoter was deleted maternally. As with the KvDMR deletion, removal of the Kcnq1ot1 promoter does not affect Igf2 imprinting (data not shown). This mutation further delineates the sequences that are nec- essary for the paternal silencing of the genes in the region and demonstrates that transcription of Kcnq1ot1 is required for imprinting.

\section{Premature termination of Kcnq1ot1 transcript}

Deletion of the Kcnq1ot1 promoter abolishes both the act of transcription as well as the transcript itself. As such, it is not possible to determine which of these is critical for the mechanism of imprinting control. Experiments exploiting an artificial episomal transfection system suggested that the transcript itself might play a role in gene silencing (Thakur et al. 2004). To assess in the genomic context whether the Kcnq1ot1 transcript is involved in the silencing of flanking genes, we used homologous recombination in ES cells to insert a poly(A)based transcription stop element $\sim 1.5 \mathrm{~kb}$ downstream of the Kcnq1ot1 start site (Fig. 5A). With this strategy, Kcnq1ot1 transcription should be initiated, but a significantly shorter transcript produced in place of the $\sim 60-\mathrm{kb}$ Kcnq1ot1 transcript.

Once mice with germline transmission of the mutation were obtained (Fig. 5B,C), we verified that initiation of transcription at Kcnq1ot1 was not perturbed by the insertion of the stop signal by employing an RNase protection probe that spanned the site of insertion of the element (Probe D in Fig. 5). RNAs prepared from tissues of animals that inherited the mutation paternally protected a smaller fragment compared with wild-type animals, indicating that transcription was preserved at the locus. The absence of a protected fragment upon maternal transmission showed that the stop signal had no effect on the silencing of the transcript on the maternal chromosome. When a 261-bp probe (probe E) located downstream of the stop signal was used in the same assay, no transcript was detected from the paternally inherited mutant allele (Fig. 5E). This establishes that the stop signal was effective at terminating transcription.

We tested the effect of the premature termination of Kcnq1ot1 on the imprinting of seven maternally expressed genes using E11.5 embryos and placentae (Fig. $6 \mathrm{~A})$. On the paternal allele, premature termination of the Kcnq1ot1 transcript led to the derepression of the paternal copies of all seven genes. In contrast, the insertion of the stop signal on the maternal chromosome had no impact on their expression.

RNase protection analysis was also employed to more accurately assess the degree of derepression of a representative gene in the cluster, Tssc4. As shown in Figure $6 \mathrm{~B}$, when the mutant $\mathrm{C} 57 \mathrm{BL} / 6$ allele is inherited paternally, Tssc4 is expressed at levels comparable to the $M$. spretus allele. Thus we conclude that either the Kcnq1ot1 transcript itself, or the elongation of its transcription beyond the termination signal inserted $1.5 \mathrm{~kb}$ downstream of its promoter, is necessary for imprinting in the region.

\section{Deletion of Kcnq1ot1 5' repeats}

We next sought to determine whether there are specific sequences within the Kcnq1ot1 transcript that are nec- 
Mancini-DiNardo et al.

A

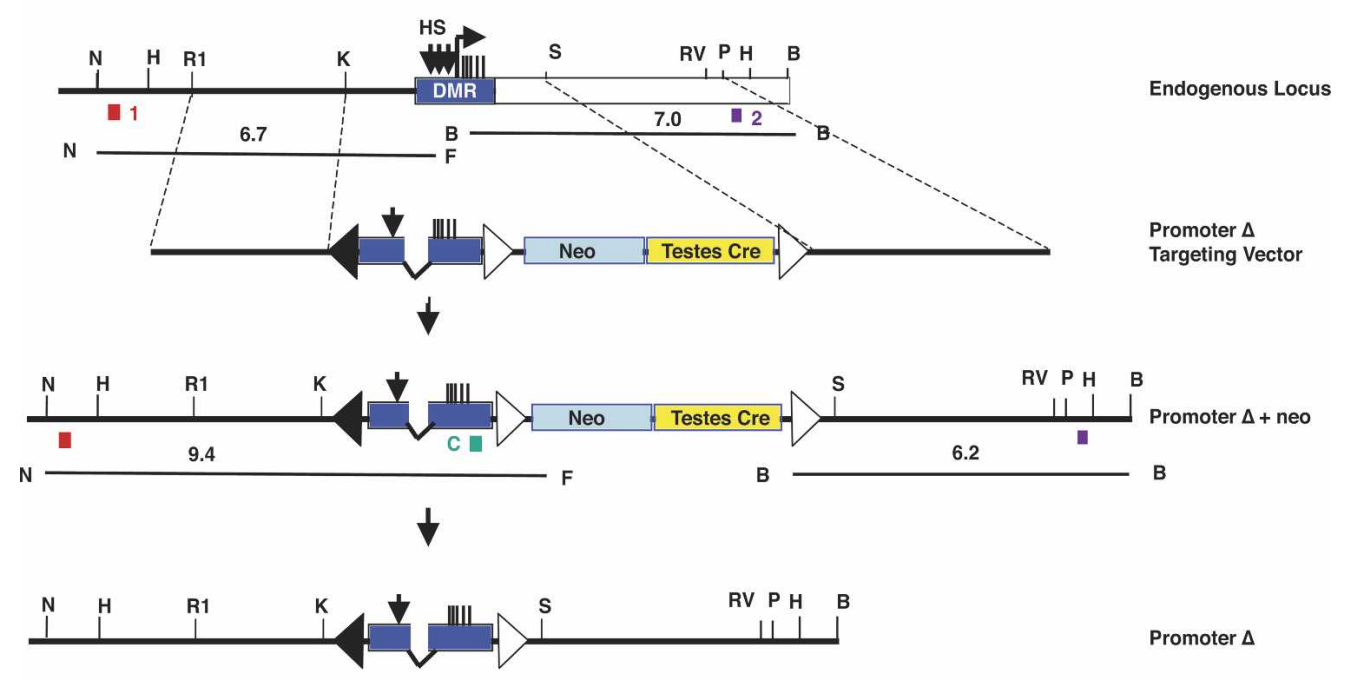

B

Probe 2

C

D
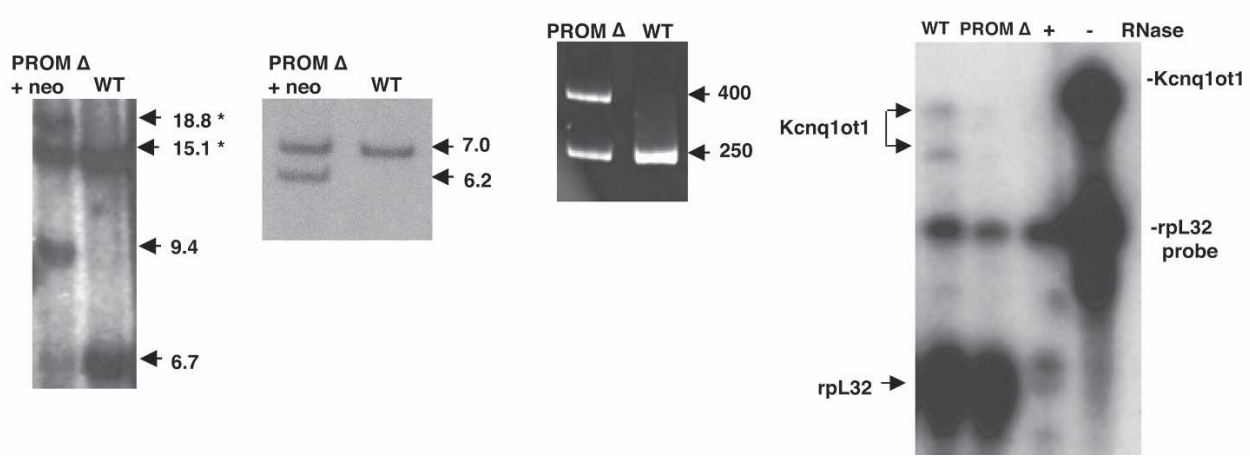

Figure 3. Deletion of the Kcnq1ot1 promoter. $(A)$ The endogenous locus is depicted as in Figure 1. The promoter $\Delta$ targeting vector contains a 244-bp deletion of the Kcnq1ot1 minimum promoter region and two DNase I hypersensitive sites, as well as the neomycin resistance gene (neo) and the Cre recombinase gene driven by a testes-specific promoter (testes-cre), flanked by loxP sites (open triangles). The loxP site at the $5^{\prime}$ end of the KvDMR (closed triangle) contains point mutations that reduce its recombination frequency with the downstream sites. The positions of the probes used in $B$ (numbered colored boxes) and the fragments that are detected are indicated. (H) HindIII; (R1) EcoRI; (K) KpnI; (F) FspI; (P) PstI; (S) SspI; (RV) EcoRV; (B) BamHI; (N) NheI. (B) Southern blot analysis of DNAs prepared from wild-type (WT) and heterozygous Prom $\Delta+$ neo mice after digestion with restriction enzymes and hybridization with the external probes as indicated in $A$. The asterisks denote the presence of additional bands that are the result of methylation of FspI sites. In wild-type cells, a 15.1-kb band derives from methylation of the maternal allele and the 6.7-kb band from the unmethylated paternal allele. In targeted ES cells, the targeted paternal allele produces both a new 9.4-kb band created by a FspI site in the neo gene and an additional $18.8-\mathrm{kb}$ band when that site is methylated. $(C)$ DNA from Prom $\Delta(-n e o)$ and wild-type (WT) mice was amplified by PCR using primers that span the neo and testes cre sequences that yield a 250-bp product derived from amplification of the nontargeted allele and a 400-bp product from the $\operatorname{Prom} \Delta(-n e o)$ allele (Table 1). (D) RNA protection of placental RNA from wild-type $(\mathrm{WT})$ and $M$. spretus $\times \operatorname{Prom} \Delta$ mice (Prom $\Delta$ ) was performed using probe C located at the $3^{\prime}$ end of the DNA repeats in KvDMR and an rpL32 ribosomal protein RNA probe as a control. Radiolabeled probes were incubated in the presence $(+)$ and absence $(-)$ of RNase and yeast RNA.

essary for imprinting control at this locus. We previously identified five evolutionarily conserved 30-bp repeated sequences at the $5^{\prime}$ end of the Kcnq1ot1 transcript (Mancini-DiNardo et al. 2003). Repeated DNA elements are common features of imprinted gene clusters, and in the case of $\mathrm{X}$ chromosome inactivation, repeated sequences at the 5' end of the Xist noncoding RNA have been implicated in gene silencing (Wutz et al. 2002). To test the role of the repeated sequences in the $5^{\prime}$ end of the Kcnq1ot1 transcript in imprinting, we deleted a 657-bp region of the Kcnq1ot1 gene containing these repeats. In the previous experiment, the repeats are upstream of the 


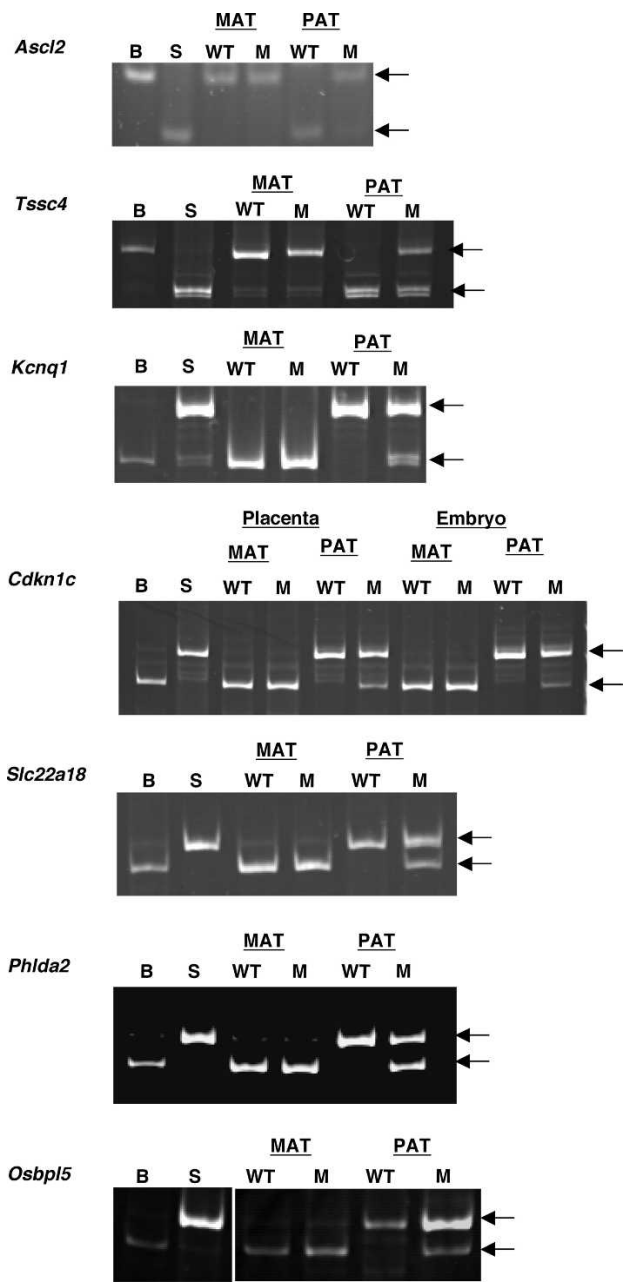

Figure 4. Effect of Kcnq1ot1 promoter deletion on imprinting. Allele-specific RT-PCR assays were used to analyze the expression of the genes listed on the left using primers specific for each transcript (Table 2). Analysis was performed on E11.5 placental RNAs and in embryo RNAs (for $C d k n 1 c$ ), isolated from offspring of reciprocal crosses between heterozygous Prom $\Delta$ and $M$. spretus mice (M) as well as their wild-type littermates (WT). (MAT) Prom $\Delta \times M$. spretus; (PAT) M. spretus $\times \operatorname{Prom} \Delta$; (B) $\mathrm{C} 57 \mathrm{BL} / 6$; (S) M. spretus. The arrows on the right refer to the allele-specific products.

stop signal and as such are contained within the truncated Kcnq1ot1 transcript. Thus, if these elements are necessary, they cannot be sufficient for imprinting. Following the correct targeting in ES cells and the germline transmission of the mutant allele (Fig. 7A-C), we tested whether the deletion affected expression of the Kcnq1ot1 transcript using an RNase protection probe that spanned the $3^{\prime}$ end of the deletion. As shown in Figure 7D, a shortened Kcnq1ot1 transcript was detected, indicating that the loss of the repeats had no effect on the production or stability of the RNA. When we used allele-specific RT-PCR assays to examine the expression of the imprinted genes in the region, no disruptions in imprinting were noted on either the maternal or paternal chromosomes (Fig. 8).

\section{Tissue distribution of Cdkn1c imprinting}

$C d k n 1 c$ is one of the best-studied imprinted genes in this cluster. It is involved in embryonic growth control and is likely to have a role in the etiology of Beckwith Wiedemann syndrome in humans (Hatada et al. 1996; O'Keefe et al. 1997; Lam et al. 1999; Maher and Reik 2000). Cdkn1c is faithfully imprinted in all mouse tissues in which it is expressed, from early embryonic development through adulthood. In contrast, the majority of the other imprinted genes in the cluster show tissue-specific imprinting that is often lost in neonates (Hatada and Mukai 1995; Caspary et al. 1998; Gould and Pfeifer 1998). We have examined the imprinting status of Cdkn1c in multiple tissues in newborn and adult mice bearing each of three mutations. We determined that when the DMR $\Delta$, Prom $\Delta$, and Term mutations were inherited paternally, every tissue analyzed (brain, heart, liver, lung, spleen, kidney) displayed biallelic expression of $C d k n 1 c$ (data not shown).

\section{Methylation analysis of the Kcnq1ot1 promoter}

The critical role of gametic methylation in the establishment and maintenance of genomic imprinting has been well established (Li et al. 1993; Bourc'his et al. 2001; Hata et al. 2002; Kaneda et al. 2004). A number of ICRs acquire their differential methylation during gametogenesis and preserve the pattern after fertilization at a time when the zygotic genome is undergoing significant epigenetic reprogramming (Kafri et al. 1992; Stoger et al. 1993; Tremblay et al. 1995; Davis et al. 2000). Furthermore the loss of methylation in mutant mice that lack Dnmt1 and Dnmt3a, genes encoding DNA methyltransferases, has been shown to disrupt imprinting of multiple genes (Li et al. 1993; Bourc'his et al. 2001).

In wild-type mice, the Kcnq1ot1 promoter within the KvDMR is heavily methylated selectively on the maternal chromosome, and that methylation is acquired during oogenesis (Engemann et al. 2000). The paternal allele is unmethylated, allowing for the transcription of Kcnq1ot1. Thus it is formally possible that the loss of silencing of the genes in the Term mutants could be occurring indirectly through inappropriate acquisition of DNA methylation on the paternal KvDMR allele, and not because of the truncation of the transcript. To assess this possibility we undertook sodium bisulfite analysis of DNA methylation of the KvDMR in Term mice and in $\operatorname{Rep} \Delta$ mice as a control. To distinguish the parental chromosomes, we sequenced progeny from crosses between mutant and congenic $M$. spretus mice.

As shown in Figure 9, a 537-bp subregion of the KvDMR containing $23 \mathrm{CpG}$ dinucleotides was unmethylated in E13.5 embryos on the Term paternal allele, in a manner indistinguishable from that in Rep $\Delta$ mice, where imprinting is unaffected. As expected, the $M$. spretus maternal alleles in both instances are heavily methylated. Thus we conclude that it is the loss of the fulllength Kcnq1ot1 transcript, and not a change in the methylation pattern of the KvDMR, that is responsible for the loss of imprinting in Term mice. 
Mancini-DiNardo et al.

A
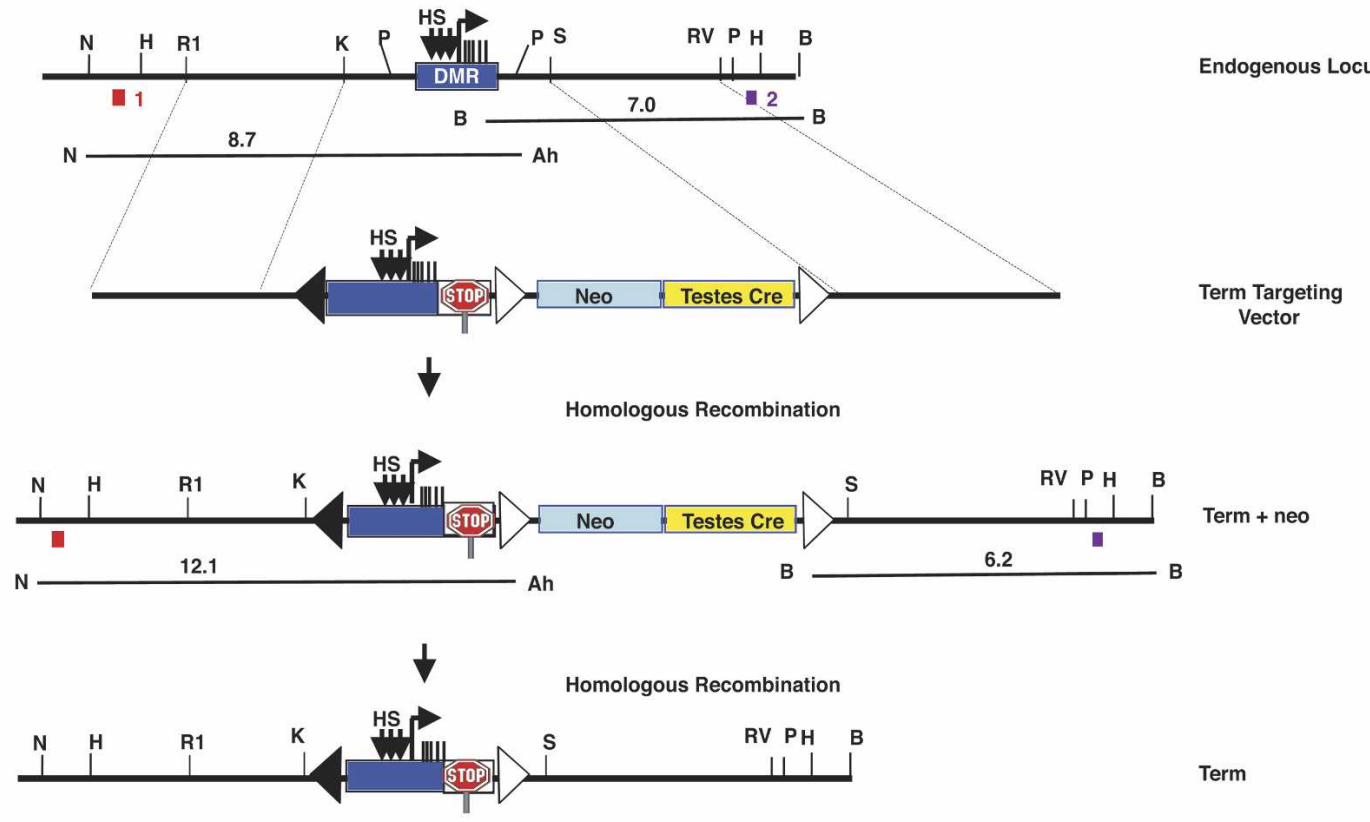

Term
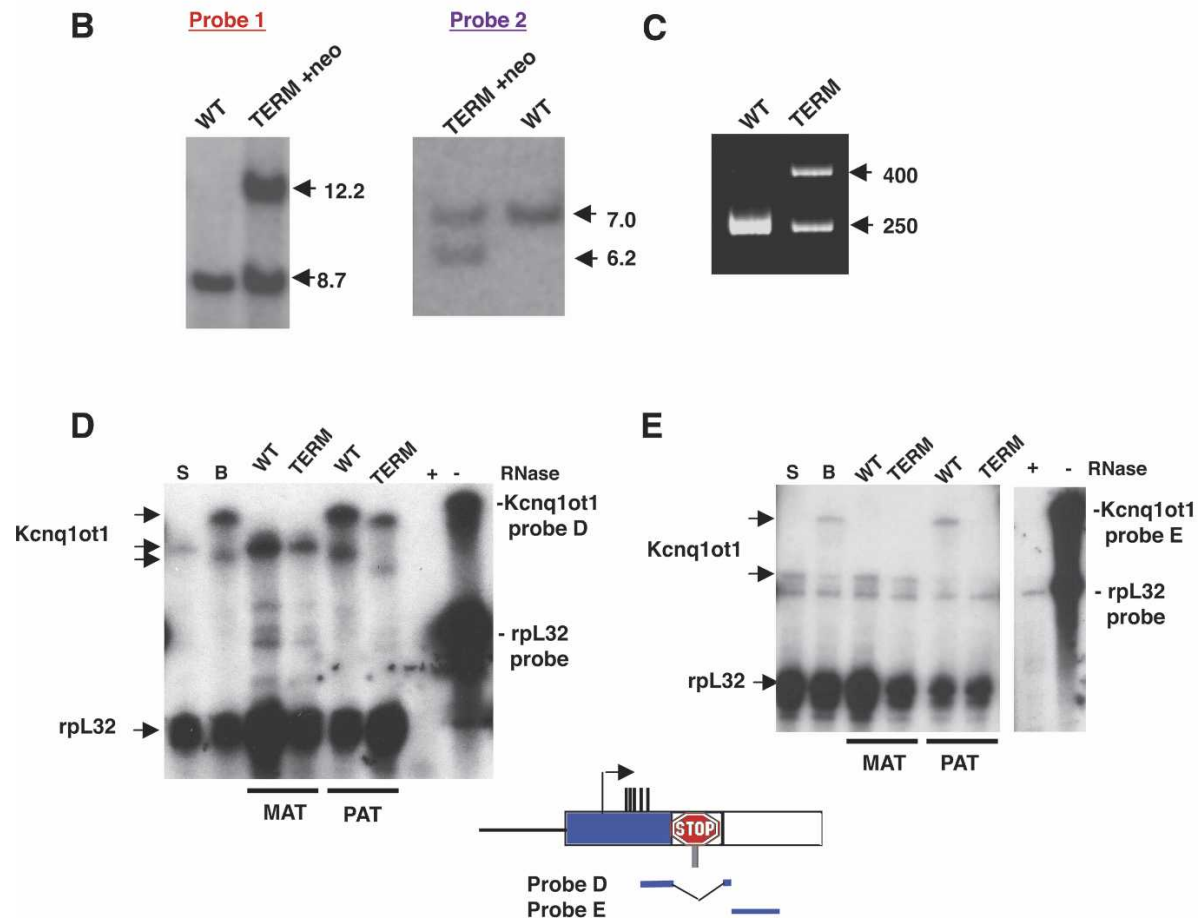

Figure 5. Termination of the Kcnq1ot1 transcript. (A) The endogenous locus is depicted as in Figure 1. The Term targeting vector contains a poly(A)-based transcriptional stop element (stop sign) that is inserted $1.5 \mathrm{~kb}$ downstream of the Kcnq1ot 1 transcription start site. The rest of the vector is described in the legend for Figure 3. The positions of the probes used in $B$ and the positions of the restriction fragments that are detected are indicated. (N) NheI; (H) HindIII; (R1) EcoRI; (K) KpnI; (P) PstI; (S) SspI; (RV) EcoRV; (B) BamHI; (Ah) AhdI. (B) Southern blot analysis of DNAs prepared from wild-type (WT) and Term +neo mice after digestion with restriction enzymes and hybridization with the external probes as indicated in $A$. (C) DNA from Term (-neo) and wild-type (WT) cells was amplified by PCR using primers as described in the legend for Figure 3C. $(D, E)$ RNase protection of E13.5 placental RNAs of wild-type (WT) and heterozygous Term embryos. Probe D spans the integration site of the poly(A) terminator and probe E is derived from downstream of the poly(A) terminator (see diagram). An rpL32 ribosomal protein RNA probe was included as a control. Radiolabeled probes were incubated in the presence $(+)$ and absence $(-)$ of RNase and yeast RNA. 
A

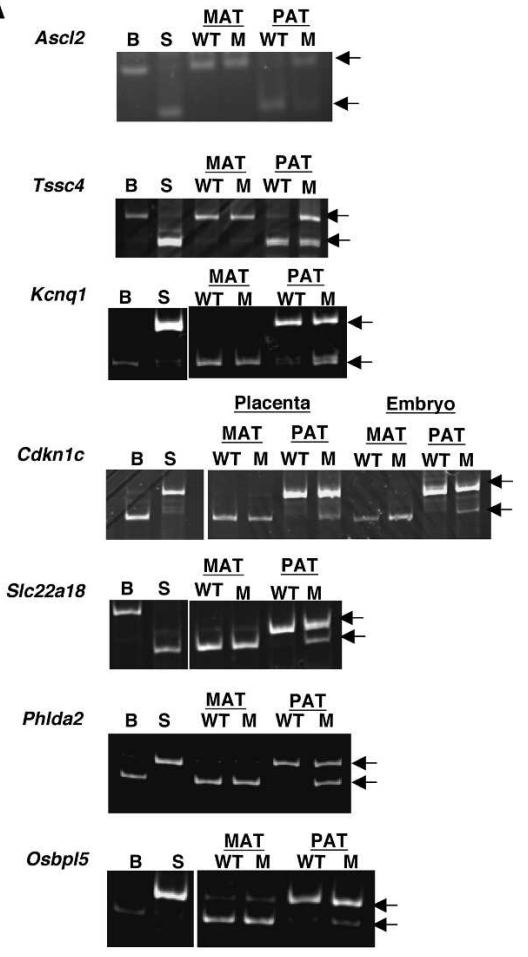

B

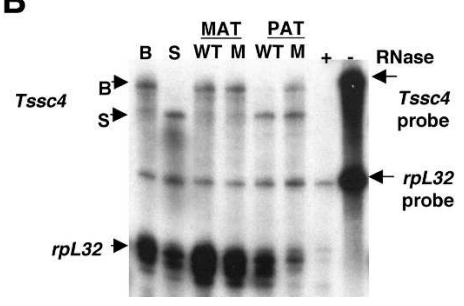

Figure 6. Effect of premature termination of the Kcnq1ot1 transcript on imprinting. (A) Allele-specific RT-PCR assays were used to analyze the expression of the genes listed on the left using primers specific for each transcript (Table 2). Analysis was performed on E11.5 placental RNAs and in embryo RNAs (for $C d k n 1 c$ ), isolated from offspring of reciprocal crosses between heterozygous Term $\Delta$ and $M$. spretus mice $(\mathrm{M})$ as well as their wild-type littermates (WT). (MAT) Term $\Delta \times M$. spretus; (PAT) M. spretus $\times$ Term $\Delta_{\text {; }}$ (B) C57BL/6; (S) M. spretus. The arrows on the right refer to the allele-specific products. (B) Allelespecific RNase protection analysis was used to determine the levels of Tssc4 RNA in E11.5 and E13.5 placentae isolated from offspring of heterozygous Term $\times$ M. spretus mice $(\mathrm{M})$ as well as their wild-type littermates (WT). An rpL32 ribosomal protein RNA probe was included to control for RNA amount. Radiolabeled probes were incubated in the presence $(+)$ and absence $(-)$ of RNase and yeast RNA. (MAT) Term $\Delta \times M$. spretus; (PAT) $M$. Spretus $\times$ Term $\Delta$.

\section{Discussion}

Two distinct mechanisms for silencing imprinted genes have been described to date. The first mechanism was identified at the H19/Igf2 locus, where a bifunctional ICR that lies between the paternally expressed Igf2 gene and the maternally expressed $H 19$ gene acts as a nucleus for the spread of DNA methylation on the paternal allele and a chromatin insulator on the maternal allele (Bell and Felsenfeld 2000; Hark et al. 2000; Kaffer et al. 2000; Kanduri et al. 2000). The activity adopted by the ICR is determined by its methylation status. The second mechanism for silencing was first described for the $I g f 2 r$ imprinted gene cluster on mouse chromosome 17. In this case the ICR is a large maternally methylated CpG island that serves as a promoter for a noncoding RNA, Air, that is paternally expressed and contained within an intron of the maternally expressed Igf2r gene (Stoger et al. 1993; Wutz et al. 1997). Using a strategy very similar to the one employed in this study, Sleutels et al. (2002) showed that synthesis of the Air transcript itself is required to mediate repression of $I g f 2 r$, as well as other genes in the cluster in cis. The authors postulated that the Air transcript may have a direct role in establishing a chromatin state on the paternal chromosome that represses gene expression bidirectionally.

In this report we provide strong evidence that the imprinting mechanism at the Cdkn1c-Kcnq1-Ascl2 imprinted gene cluster falls into the second class. As in the case of the Igf2r ICR, the KvDMR is maternally methylated and serves as a promoter for a paternally expressed noncoding transcript (Smilinich et al. 1999). When a large portion of the KvDMR was deleted in the mouse germline, imprinting of neighboring genes was eliminated, thus establishing the central role of the element in imprinting (Fitzpatrick et al. 2002). We have extended this finding by examining the consequences of deleting just $244 \mathrm{bp}$ of the DMR coinciding with the minimal Kcnq1ot1 promoter. The loss of imprinting of all genes in the cluster identified the production of the noncoding transcript as a critical element in the imprinting mechanism. By inserting a strong transcriptional stop signal into the Kcnq1ot1 transcription unit, we established that the imprinting mechanism requires either the production of the transcript itself or its elongation past the engineered termination signal that is $1.5 \mathrm{~kb}$ downstream of the transcription start site. This finding is consistent with previous results using a stable transfection system that suggested that elongation of a segment of Kcnq1ot1 was required for silencing reporter genes (Thakur et al. 2004). By showing that premature termination of the Kcnq1ot1 transcript results in the loss of imprinting of at least seven genes normally silent on the paternal allele, including Osbp15, which was not assessed in the earlier report (Fitzpatrick et al. 2002), we extend the regulatory influence of the KvDMR to a region encompassing at least $775 \mathrm{~kb}$ from Ascl2 to Osbpl5.

One way to distinguish between a role for the transcript itself, versus the extent of its elongation, is to show that specific sequences within the transcript are required for gene silencing. For example, Wutz et al. (2002) identified a distinct domain within the noncoding $X$ ist RNA that is required for the inactivation of genes on the $\mathrm{X}$ chromosome in cis. The Xist silencing domain resides at the $5^{\prime}$ end of the RNA and contains seven or eight copies of a 25-bp repeated sequence that is conserved between mice and humans (Brown et al. 1992; Hendrich et al. 1993). The authors demonstrated that a 
Mancini-DiNardo et al.
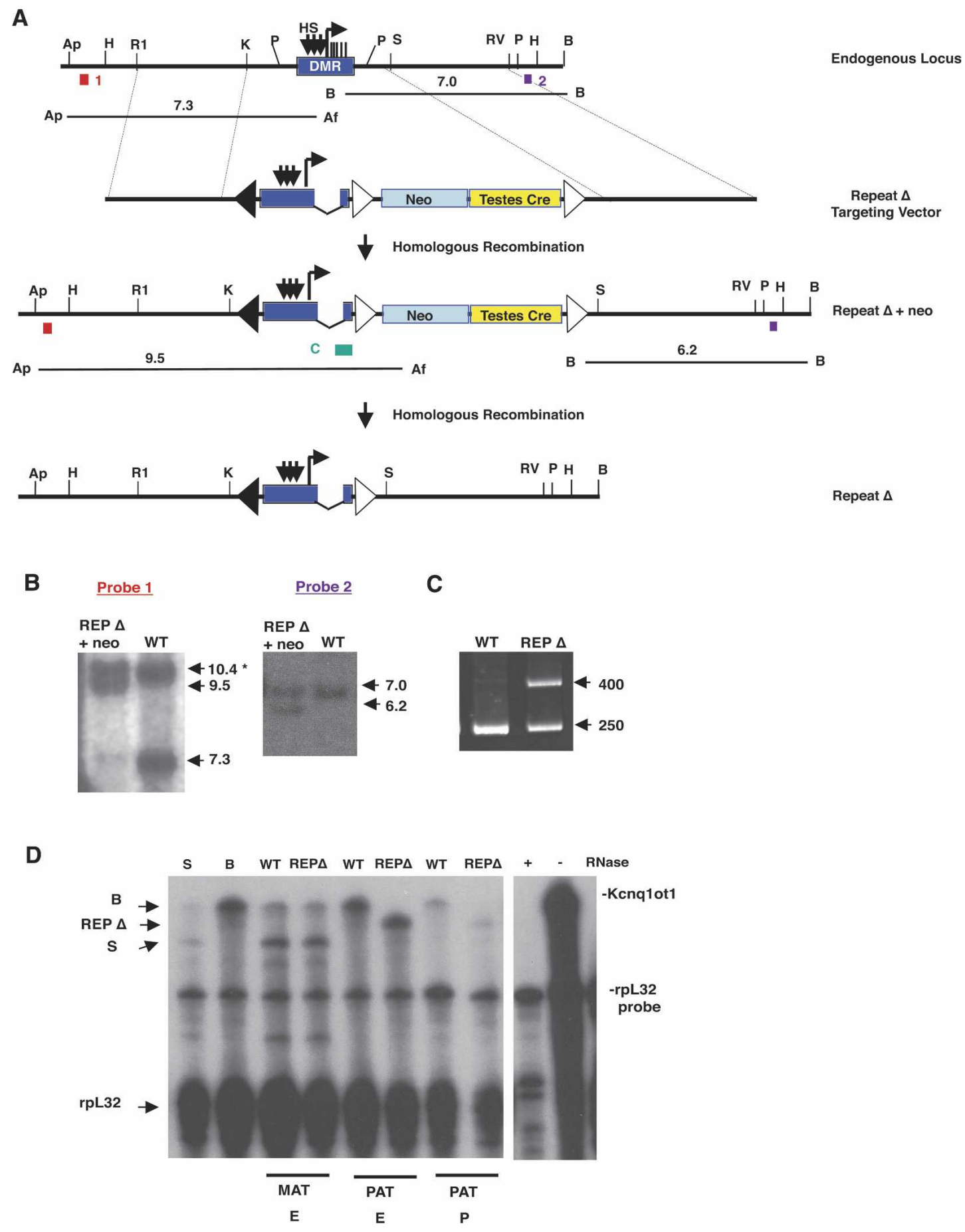

Figure 7. Deletion of DNA repeats in the Kcnq1ot1 transcript. (A) The endogenous locus is depicted as in Figure 1 . The Rep $\Delta$ targeting vector contains a 657-bp deletion of five repeats within the Kcnq1ot1 transcript. The rest of the vector is described in the legend for Figure 2. The positions of the probes used in $B$ and the sizes and positions of the restriction fragments that are detected are indicated. (Ap) ApaLI; (H) HindIII; (R1) EcoRI; (K) KpnI; (P) PstI; (Af) AfeI; (S) SspI; (RV) EcoRV; (B) BamHI. (B) Southern blot analysis of DNAs prepared from wild-type (WT) and Rep $\Delta+$ neo mice after digestion with restriction enzymes and hybridization with the external probes as indicated in $A$. The asterisk denotes the presence of a 10.4-kb band that results from the methylation of an AfeI site on the untargeted maternal chromosome. $(C)$ DNA from Rep $\Delta(-n e o)$ and wild-type (WT) cells was amplified by PCR using primers as described in the legend for Figure 3C. (D) RNase protection of placental (P) and embryo (E) RNAs of wild-type (WT) and Rep $\Delta$ embryos in which the Rep $\Delta$ is inherited either maternally (MAT) or paternally (PAT). Probe C spans the $3^{\prime}$ end of the repeat region that is deleted. An rpL32 ribosomal protein RNA probe was included to control for RNA quantity. Radiolabeled probes were incubated in the presence (+) and absence (-) of RNase and yeast RNA. 
Ascl2

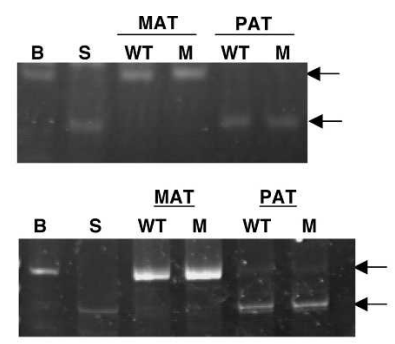

Kenq1

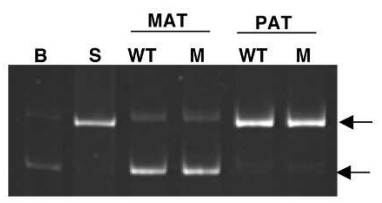

Cakn1c

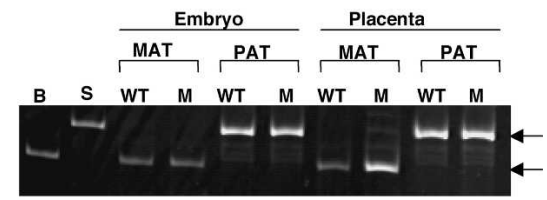

SIc22a18

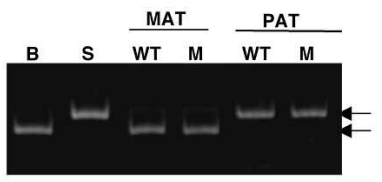

PhIda2

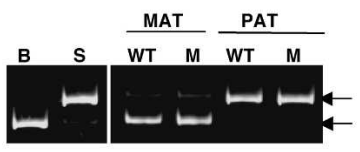

Osbp/5

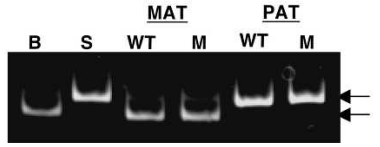

Figure 8. Effect of deletion of DNA repeats in the Kcnq1ot1 transcript on imprinting. Allele-specific RT-PCR assays were used to analyze the expression of the genes listed on the left using primers specific for each transcript (Table 2). Analysis was performed on E11.5 placental RNA and in embryo RNAs (for Cdkn1c), isolated from offspring of reciprocal crosses between heterozygous Rep $\Delta$ and $M$. spretus mice $(\mathrm{M})$ as well as their wild-type littermates (WT). (MAT) Rep $\Delta \times M$. spretus; (PAT) $M$. spretus $\times \operatorname{Rep} \Delta$; (B) C57BL/6; (S) M. spretus. The arrows on the right refer to the allele-specific products.

deletion of the repeated sequences resulted in a transcript that was able to coat the $\mathrm{X}$ chromosome destined to be inactivated, but was no longer able to repress transcription. We previously identified the presence of five repeats located at the $5^{\prime}$ end of the Kcnq1ot1 transcript that are highly conserved in human, mouse, and galago (Mancini-DiNardo et al. 2003; Paulsen et al. 2005). Arguing by analogy to Xist, these repeats were potential candidates for a cis-acting silencing element within the Kcnq1ot1 transcript. However, as shown in Figure 8, the loss of these $5^{\prime}$ repeated sequences does not affect the imprinting of any of the genes in the cluster. Thus, although repeated sequences seem to be a common feature of imprinting gene domains, in only two instances have they been shown to play a mechanistic role (Reinhart et al. 2002; Yoon et al. 2002).

It remains to be established how noncoding RNAs like Air and Kcnq1ot1 might affect gene silencing in cis. The simplest model, whereby the RNAs destablilize sense transcripts through the formation of double-stranded RNAs, is difficult to reconcile with the genomic organization of the imprinted gene clusters. In the case of Kcnq1ot1, this model could explain the silencing of Kcnq1, but it cannot explain the silencing of $C d k n 1 c$ and the other more telomeric genes that are transcribed in the same direction of Kcnq1ot1. It is also difficult to explain by this model the transient imprinting of Kcnq1, which is only imprinted during embryonic and fetal development, but becomes biallelic in tissues that continue to express Kcnq1ot1 later in development (Mancini-DiNardo et al. 2003). An alternative RNA-dependent silencing mechanism is RNA interference (RNAi), in which the noncoding transcript is processed into small RNAs, some fraction of which would base-pair with the mRNA or DNA of the imprinted genes in the cluster (Dykxhoorn et al. 2003). Such a model would have to incorporate an additional constraint to restrict silencing in cis.

There are a number of transcription-dependent models that are also plausible candidates for the silencing of genes in the Cdkn1c-Kcnq1-Ascl2 cluster. For example, the repression could occur via the movement of RNA polymerase through the length of the 60-kb Kcnq1ot1 gene, leading to topological changes that attract repressive chromatin proteins in cis. In this model the actual sequences transcribed are not relevant, only the production of a full-length transcript. Such a model must accommodate the fact that embedded in the $775-\mathrm{kb}$ cluster are several genes that escape silencing on the paternal chromosome, for example, Trpm5 between Kcnq1 and Tssc4 (Enklaar et al. 2000). However, there is ample precedent for this; for example, there are numerous genes known to escape inactivation on the inactive $\mathrm{X}$ chromosome (Carrel and Willard 2005) and silencing by Drosophila heterochromatin (Hoskins et al. 2002). Alternatively Kcnq1ot1 could participate in an RNA-dependent transcriptional silencing mechanism in which RNAs attract both DNA methyltransferases and repressive chromatin proteins (Matzke and Birchler 2005). Such a mechanism has been proposed for the role of Xist RNA in $\mathrm{X}$ chromosome inactivation, where it has been shown to bind to and coat the entire inactive $\mathrm{X}$ chromosome prior to gene inactivation (Ogawa and Lee 2002).

Whatever the specific details of how Kcnq1ot1 transcription sets up the imprinting of the genes in the cluster, it is likely that a variety of well-known mechanisms are then exploited to maintain and replicate the silent state at each cell division. An extensive analysis of DNA methylation in the region has revealed that other than KvDMR, only Cdkn1c and S1c22a18 are associated with substantial allele-specific methylation in their vicinities (Yatsuki et al. 2002; Lewis et al. 2004). This finding is consistent with reports that the imprinting of genes such as Osbp15, Kcnq1, Tccs4, and Ascl2 in extraembryonic 
Mancini-DiNardo et al.

Figure 9. CpG methylation analysis at KvDMR. A 537-bp region spanning the Kcnqt1ot1 promoter, which includes 23 CpG dinucleotides, was amplified from E11.5 and E13.5 embryos and yolk sac following treatment with sodium bisulfite. The asterisk refers to a polymorphism between M. spretus and C57BL/6 that was used to distinguish the parental alleles. DNA from $M$. spretus $\times$ Term embryos $(A)$ and $M$. spretus $\times \operatorname{Rep} \Delta$ embryos $(B)$. Black ovals indicate methylated CpGs, open ovals indicate unmethylated CpGs, and gray ovals represent unreadable sequence.

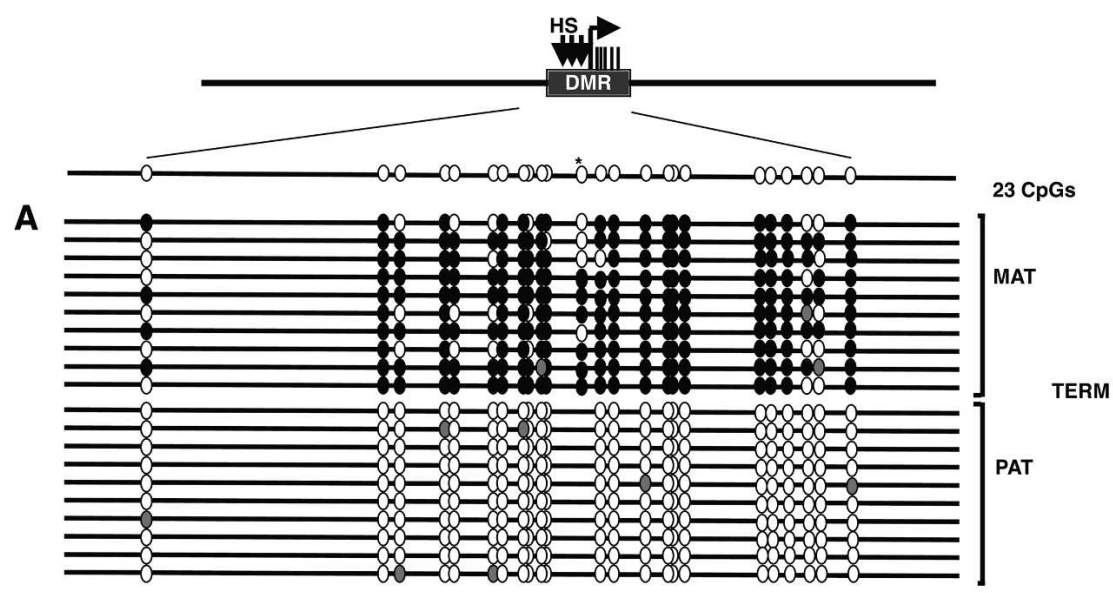

B

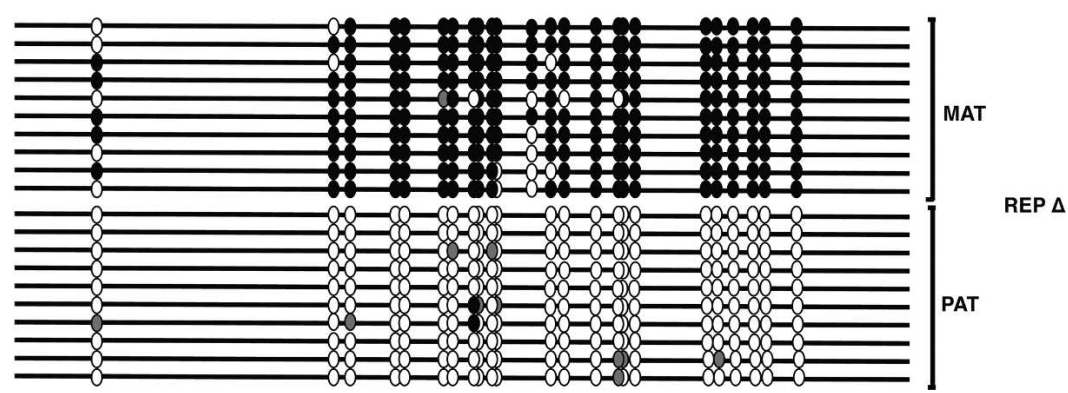

tissues is unaffected by the loss of DNA methylation in mice that are mutant for the maintenance DNA methyltransferase, Dnmt1 (Caspary et al. 1998; Tanaka et al. 1999; Lewis et al. 2004). Interestingly the imprinting of Kcnq1 was lost in the embryo but not the trophoblast of $D n m t^{-/-}$embryos, suggesting tissue-specific differences in the relative importance of DNA methylation to imprinting. These findings suggest that somatic differential DNA methylation can only partially explain the imprinting of genes in the cluster. Indeed even for $C d k n 1 c$, its paternal-specific methylation is not inherited from the gametes but is established post-implantation during the wave of de novo genome methylation (Engemann et al. 2000). Analysis of preimplantation embryos revealed maternal-specific expression of $C d k n 1 c$ prior to the establishment of its differential methylation, implying that methylation does not contribute to the establishment of the imprinted state at $C d k n 1 c$, but adds another level of stability, effectively reinforcing the imprinted state within the embryo (Bhogal et al. 2004).

The Cdkn1c-Kcnq1-Ascl2 cluster is characterized by extensive differential histone modifications in placenta, but not embryo, with the exception of the KvDMR and Cdkn1c, which are differentially associated with histones in both tissues (Lewis et al. 2004; Umlauf et al. 2004). Histone modifications form part of a complex histone code, in which transcriptionally inactive genes are associated with deacetylated histones $\mathrm{H} 3$ and $\mathrm{H} 4$ as well as dimethylation at Lys 9 and trimethylation at Lys 27 on histone H3 (Nielsen et al. 2001). In contrast, active genes display histone acetylation at Lys 9 and Lys 14 of histone $\mathrm{H} 3$ as well as dimethylation of Lys 4 of histone H3. As expected, upon paternal deletion of the KvDMR, the paternal alleles of several genes in the cluster became associated with histone $\mathrm{H} 3$ acetylated at Lys 9 and methylated at Lys 4 , characteristic of an active transcriptional state (Lewis et al. 2004).

In addition to the histones themselves, repressive chromatin contains other proteins that are critical to establishing the repressed state. One such class of proteins is the Polycomb group (PcG), which promote gene silencing via histone methyltransferase activity as well as through their association with histone deacetylases. PcG proteins are able to repress gene activity over a considerable distance, likely by spreading a repressive chromatin state (Wang et al. 2004). The Polycomb group protein complex, which includes embryonic ectoderm development (Eed), enhancer-of-zeste homolog-2 (Ezh2), and suppressor-of-zeste-12 (Suz12) is known to methylate Lys 27 of histone H3 (Cao and Zhang 2004), and associates with the silent paternal alleles of Ascl2 and Cdkn1c in placenta, but not the silent promoter of Kcnq1ot1 (Umlauf et al. 2004) This is consistent with the report that Eed-deficient embryos displayed partial loss of imprinting of these genes, but not Kcnq1ot1 (Mager et al. 2003), which presumably is primarily regulated by its extensive gametic methylation.

In summary, our current model for the imprinting of the genes within the $C d k n 1 c-K c n q 1-A s c l 2$ gene cluster proposes that the differential gametic DNA methylation of KvDMR establishes the initial difference between the parental chromosomes and leads to paternal-specific 
transcription of Kcnq1ot1. By a mechanism that remains to be determined, the transcription of Kcnq1ot1 early in development leads to the bidirectional recruitment of silencing factors in cis that confer DNA methylation and histone modifications that do not occur on the maternal chromosome. The challenge now becomes to connect at the molecular level the transcription of Kcnq1ot1 to the presence of these epigenetic modifications in the region.

\section{Materials and methods}

Generation of DMRs, Proms, Term, and Reps mice

To generate the DMR $\Delta$ targeting vector, a selection cassette consisting of the neomycin resistance gene (neo) was inserted in place of a 3.6-kb PstI fragment spanning the Kcnq1ot1 promoter and KvDMR CpG island (Fig. 1A). To create the Prom $\Delta$, Term, and Rep $\Delta$ targeting vectors, modified versions of a 3.5-kb KpnISspI fragment that spans the KvDMR were inserted between the two 5 ' lox $\mathrm{P}$ sites in the vector described in Schoenherr et al. (2003) (Figs. 3A, 5A, 7A). The modifications were, in the Proms vector, deletion of a 244-bp BsrGI-SfoI fragment to disrupt the Kcnq1ot1 promoter; in the Rep $\Delta$ targeting vector, deletion of a 657-bp SfoI-AvrII fragment to delete the repeats; and in the Term vector, a transcriptional stop element composed of four tandem SV40 poly(A) sequences (GenBank accession no. AF316141.1) derived from a 3.4-kb XhoI-EcoRI fragment within the pBS. DAT-LoxStop vector (kindly provided by Tyler Jacks' laboratory at Massachussetts Institute of Technology, Cambridge, MA) was placed at an EcoRI site $1.5 \mathrm{~kb}$ downstream of the transcription start site.

The targeting vectors were then individually electroporated into CJ7 mouse ES cells. The cells were grown on neomycinresistant primary mouse embryonic fibroblasts for a period of 7-10 d under selective media. Surviving colonies were expanded in 96-well plates, and DNA was prepared and digested with restriction enzymes for Southern blot analysis to identify correctly targeted cells. For all constructs, a 3' external probe was used to detect a 7-kb BamHI fragment in wild-type cells and a 6.2-kb fragment in correctly targeted cells that exploits a BamHI site in the vector. For the DMR $\Delta$ targeted allele we used as a probe a 340-bp PCR product generated from cloned genomic DNA (probe 2: nucleotides 51907-52247, NR001461; Fig. 1B), and for the Prom $\Delta$, Term, and Rep $\Delta$ targeted alleles we used a 379-bp PstI-HindIII fragment (probe 2; Figs. 3B, 5B, 7B). To detect the 5 ' end of the Prom $\Delta$, Term, and Rep $\Delta$ targeted alleles, a 1.2-kb AseI-HindIII fragment (probe 1) was employed with a variety of enzymes, depending on the construct (Figs. 3B, 5B, 7B). For the DMR $\Delta$ targeted allele, we used a 600-bp XhoIHindIII fragment (probe 1) (Fig. 1B).

Correctly targeted clones were injected into C57BL/6 blastocysts and implanted into pseudopregnant mice. Male chimeras were bred to C57BL/6 females and their agouti progeny were genotyped by PCR using DNA isolated from tails (see Table 1 for primers). In DMR $\Delta$ mutants, the neo selectable marker was subsequently removed in $\mathrm{F}_{2}$ animals by microinjecting Cre recombinase into the fertilized eggs of $F_{1}$ mutant animals. Proper excision was confirmed by Southern analysis on genomic DNA from $\mathrm{F}_{2}$ animals using a 1.1-kb PstI fragment $3^{\prime}$ of the deletion as probe (probe 3) (Fig. 1B). The Prom $\Delta$, Term, and Rep $\Delta$ targeting vectors contain the Cre recombinase (cre) gene under the control of a testes-specific promoter (Schoenherr et al. 2003). As such, the neo and cre genes were removed in the germline of male chimeras by testes-specific expression of Cre recombinase. A third variant Lox site was included 5' of the KvDMR to provide a future option for homologous recombination within the region in intact mice. To confirm excision, a PCR-based assay was utilized that yields an $\sim 400$-bp band after excision of the cassette (Table 1).

$\mathrm{F}_{1}$ and $\mathrm{F}_{2}$ mutants were crossed to $\mathrm{C} 57 \mathrm{BL} / 6$ congenic mice harboring $M$. spretus sequences at the distal chromosome 7 to provide allelic differences in parental alleles.

\section{Allele-specific RT-PCR analysis}

Total RNA from E11.5-E13.5 embryos and placentae as well as newborn mouse tissues was isolated using Trizol (Sigma) according to the manufacturer's instructions. The RNA was treated with DNase I (Stratagene) for $30 \mathrm{~min}$ at $37^{\circ} \mathrm{C}$ followed by phenol:chloroform (1:1) extraction and ethanol precipitation. The RNA was transcribed into cDNA using SuperScript First Strand (Invitrogen) and amplified using primers specific to each gene tested (Table 2). The PCR products were digested with restriction enzymes that selectively digested either the $M$. spretus or C57BL/6 allele. The products were analyzed on $10 \%$ polyacrylamide gels.

\section{Allele-specific RNase protection assay}

RNase protection assays were carried out using the RPAIII kit (Ambion). Antisense RNAs were synthesized from cDNA templates cloned into either pBluescript II KS+ or TA cloning vectors in the presence of $\left[{ }^{32} \mathrm{P}\right] \mathrm{CTP}$ and $\mathrm{T} 3, \mathrm{~T} 7$, or Sp6 polymerases.

Table 1. Primers used for genotyping PCR

\begin{tabular}{ll}
\hline Targeting vector & \multicolumn{1}{c}{ Primer sequence } \\
\hline DMR $\Delta$ & FOR 5'-CAATGGCAGGAAGCAGGTGC-3' \\
DMR $\Delta(\mathrm{WT})$ & REV 5'-CGAGAGCCAGTCCTGTGAACAG-3' \\
DMR $\Delta(\mathrm{MUT})$ & REV 5'-CTTGTGTAGCGCCAAGTGC-3' \\
DMR $\Delta$ Neo Out & FOR 5'-CAATGGCAGGAAGCAGGTGC-3' \\
Prom $\Delta$ & REV 5'-GATCCTTCTAGCTGGAGCACAAATCC-3' \\
Term & FOR 5'-CTCAGGTATCTGCCCTGTACTGCATTG-3' \\
& REV 5'-CGTAACCACGCCGAGGAGAAGCCCACCGAAGTA-3' \\
Rep $\Delta$ & FOR 5'-GTGTGCCTAGGACACCGGCTCAGGCCTTCGG-3' \\
Prom $\Delta$, Term, and Rep $\Delta$ & REV 5'-CCTTCACAAAGATCCCTCGAGCCCAATTCC-3' \\
Neo out & FOR 5'-CTCAGGTATCTGCCCTGTACTGCATTG-3' \\
\hline
\end{tabular}


Mancini-DiNardo et al.

Table 2. Primers and restriction sites used for allele-specific RT-PCR

\begin{tabular}{|c|c|c|}
\hline Gene & Primer sequence & Polymorphic enzyme \\
\hline \multirow[t]{2}{*}{ Osbp15 (Obph1) } & FOR 5'-TGGACGAAGCTGTGGTGTG-3' & BfaI \\
\hline & REV 5'-CGTCTGATTCAGAAGCGGC-3' & \\
\hline \multirow[t]{2}{*}{ Phlda2 (Tssc3, Ipl) } & FOR 5'-ACTGCGTGGAGCACACCTCT-3' & BlpI \\
\hline & REV 5'-ACACGGAATGGTGGGTTGGA-3' & \\
\hline \multirow[t]{2}{*}{ Slc22a18 (Impt1) } & FOR 5'-TGTCTGCCTGGGATGTCTG-3' & HpaII \\
\hline & REV 5'-GCCCGCCAGGAAGGAGAG-3' & \\
\hline \multirow{2}{*}{$C d k n 1 c\left(p 57^{\text {Kip2 }}\right)$} & FOR 5'-TTCAGATCTGACCTCAGACCC-3' & AvaI \\
\hline & REV 5'-AGTTCTCTTGCGCTTGGC-3' & \\
\hline \multirow[t]{2}{*}{ Kcnq1 (Kvlqt1) } & FOR 5'-GATCACCACCCTGTACATTGG-3' & PvuII \\
\hline & REV 5'-CCAGGACTCATCCCATTATCC-3' & \\
\hline \multirow[t]{2}{*}{ Tssc4 } & FOR 5'-CTGTGCGCGCTAGGATACCCTTTAA-3' & HруCH4IV \\
\hline & REV 5'-AGGTCCAGCGAGATGGGCTAGCTCC-3' & \\
\hline \multirow[t]{2}{*}{ Ascl2 (Mash2) } & FOR 5'-TGGGCTGCTCTGAGCCTACC-3' & BstNI \\
\hline & REV 5'-AAGTCCTGATGCTGCAAGGT-3' & \\
\hline
\end{tabular}

Alternative names of the genes are indicated in parentheses.

In cases where $\mathrm{T} 3$ or $\mathrm{T} 7$ polymerase was used, samples were incubated at $37^{\circ} \mathrm{C}$ for $1 \mathrm{~h}$. Probes synthesized using Sp6 were incubated at $42^{\circ} \mathrm{C}$ for $1 \mathrm{~h}$. The probes were treated with RNasefree DNase for $15 \mathrm{~min}$ at $37^{\circ} \mathrm{C}$ and purified on $8 \mathrm{M}$ urea $/ 5 \%$ polyacrylamide gels. Each probe $(20,000-80,000 \mathrm{cpm})$ was hybridized to $10 \mu \mathrm{g}$ of total RNA for at least $16 \mathrm{~h}$ at $55^{\circ} \mathrm{C}$. Following RNase digestion with a 1:50 dilution of the RNase A/T1 mix, the samples were separated on $7 \mathrm{M}$ urea/7.5\% polyacrylamide gels. Gels were then exposed to X-ray film and quantitated with a Molecular Dynamics PhosphorImager. The following probes were used for the allele-specific RPAs: Tssc4 (450 bp: nucleotides 566-1016; NM020285), Term probe D (410 bp: nucleotides 6536-6946; AF119385), Term probe E (261 bp: nucleotides 8287-8548; AF119385), and probe C, (441 bp: nucleotides 5935-6376; AF119385).

\section{Sodium bisulfite analysis}

Genomic DNA was isolated from E11.5 and E13.5 embryos and yolk sacs using the DNeasy kit (Qiagen) according to the manufacturer's instructions. The DNA was subsequently modified using the sodium bisulfite conversion protocol (Andrews et al. 1996; Mancini et al. 1998). We amplified the promoter region of Kcnq1ot1 using primers previously described (Yatsuki et al. 2002). All PCR amplifications were performed in $20-\mu \mathrm{L}$ reactions containing $\sim 150 \mathrm{ng}$ of bisulfite-treated genomic DNA. The amplification conditions were $94^{\circ} \mathrm{C}$ for $3 \mathrm{~min}$ followed by 30 cycles at $94^{\circ} \mathrm{C}(30 \mathrm{sec}), 58^{\circ} \mathrm{C}(30 \mathrm{sec})$, and $72^{\circ} \mathrm{C}(1 \mathrm{~min})$. A final 7 -min incubation at $72^{\circ} \mathrm{C}$ was also performed. Nested PCR reactions were carried out using $1 \mu \mathrm{L}$ of the previous PCR amplifications for 30 cycles under the same conditions. PCR products were gel-purified and cloned into the pCRII-TOPO vector (Invitrogen), transformed, purified, and sequenced using fluorescence cycle sequencing.

\section{Acknowledgments}

D.M.D. was supported by a post-doctoral fellowship from the Cancer Research Fund of the Damon Runyon Foundation and S.J.S.S. was supported by the New Jersey Commission on Cancer Research. This work was supported by a grant from the NIH and the investigatorship of S.M.T. from the Howard Hughes Medical Institute.

\section{References}

Andrews, J.D., Mancini, D.N., Singh, S.M., and Rodenhiser, D.I. 1996. Site and sequence specific DNA methylation in the neurofibromatosis (NF1) gene includes C5839T: The site of the recurrent substitution mutation in exon 31. Hum. Mol. Genet. 5: 503-507.

Bell, A.C. and Felsenfeld, G. 2000. Methylation of a CTCF-dependent boundary controls imprinted expression of the Igf2 gene. Nature 405: 482-485.

Bhogal, B., Arnaudo, A., Dymkowski, A., Best, A., and Davis, T.L. 2004. Methylation at mouse Cdknlc is acquired during postimplantation development and functions to maintain imprinted expression. Genomics 84: 961-970.

Bielinska, B., Blaydes, S.M., Buiting, K., Yang, T., KrajewskaWalasek, M., Horsthemke, B., and Brannan, C.I. 2000. De novo deletions of SNRPN exon 1 in early human and mouse embryos result in a paternal to maternal imprint switch. Nat. Genet. 25: 74-78.

Bourc'his, D., Xu, G.L., Lin, C.S., Bollman, B., and Bestor, T.H. 2001. Dnmt3L and the establishment of maternal genomic imprints. Science 294: 2536-2539.

Brown, C.J., Hendrich, B.D., Rupert, J.L., Lafreniere, R.G., Xing, Y., Lawrence, J., and Willard, H.F. 1992. The human XIST gene: Analysis of a $17 \mathrm{~kb}$ inactive $X$-specific RNA that contains conserved repeats and is highly localized within the nucleus. Cell 71: 527-542.

Cao, R. and Zhang, Y. 2004. The functions of E(Z)/EZH2-mediated methylation of lysine 27 in histone H3. Curr. Opin. Genet. Dev. 14: 155-164.

Carrel, L. and Willard, H.F. 2005. X-inactivation profile reveals extensive variability in X-linked gene expression in females. Nature 434: 400-404.

Caspary, T., Cleary, M.A., Baker, C.C., Guan, X.-J., and Tilghman, S.M. 1998. Multiple mechanisms regulate imprinting of the mouse distal chromosome 7 gene cluster. Mol. Cell. Biol. 18: 3466-3474.

Davis, T.L., Yang, G.J., McCarrey, J.R., and Bartolomei, M.S. 2000. The H19 methylation imprint is erased and re-established differentially on the parental alleles during male germ cell development. Hum. Mol. Genet. 9: 2885-2894.

Dykxhoorn, D.M., Novina, C.D., and Sharp, P.A. 2003. Killing the messenger: Short RNAs that silence gene expresssion. Nat. Rev. Mol. Cell Biol. 4: 457-467.

Engemann, S., Strodicke, M., Paulsen, M., Franck, O., Rein- 
hardt, R., Lane, N., Reik, W., and Walter, J. 2000. Sequence and functional comparison in the Beckwith-Wiedemann region: Implications for a novel imprinting centre and extended imprinting. Hum. Mol. Genet. 9: 2691-2706.

Enklaar, T., Esswein, M., Oswald, M., Hilbert, K., Winterpacht, A., Higgins, M., Zabel, B., and Prawitt, D. 2000. Mtr1, a novel biallelically expressed gene in the center of the mouse distal chromosome 7 imprinting cluster, is a member of the Trp gene family. Genomics 67: 179-187.

Fitzpatrick, G.V., Soloway, P.D., and Higgins, M.J. 2002. Regional loss of imprinting and growth deficiency in mice with a targeted deletion of KvDMR1. Nat. Genet. 9: 426-431.

Gould, T.D. and Pfeifer, K. 1998. Imprinting of Kvlqt1 is developmentally regulated. Hum. Mol. Genet. 7: 483-487.

Guillemot, F., Caspary, T., Tilghman, S.M., Copeland, N.G., Gilbert, D.J., Jenkins, N.A., Anderson, D.J., Joyner, A.L., Rossant, J., and Nagy, A. 1995. Genomic imprinting of Mash-2, a mouse gene required for trophoblast development. Nat. Genet. 9: 235-241.

Hark, A.T., Schoenherr, C.J., Katz, D.J., Ingram, R.S., Levorse, J.M., and Tilghman, S.M. 2000. CTCF mediates methylation-sensitive enhancer-blocking activity at the H19/Igf2 locus. Nature 405: 486-489.

Hata, K., Okano, M., Lei, H., and Li, E. 2002. Dnmt3L cooperates with the Dnmt3 family of de novo DNA methyltransferases to establish maternal imprints in mice. Development 129: 1983-1993.

Hatada, I. and Mukai, T. 1995. Genomic imprinting of p57/ KIP2, a cyclin-dependent kinase inhibitor, in mouse. Nat. Genet. 11: 204-206.

Hatada, I., Ohashi, H., Fukushima, Y., Kanetko, Y., Inoue, M., Komoto, Y., Okada, A., Ohishi, S., Nabetani, A., Morisaki, H., et al. 1996. An imprinted gene p57KIP2 is mutated in Beckwith-Wiedemann syndrome. Nat. Genet. 14: 171-173.

Hendrich, B.D., Brown, C.J., and Willard, H.F. 1993. Evolutionary conservation of possible functional domains of the human and murine XIST genes. Hum. Mol. Genet. 2: 663-672.

Hoskins, R.A., Smith, C.D., Carlson, J.W., Carvalho, A.B., Halpern, A., Kaminker, J.S., Kennedy, C., Mungall, C.J., Sullivan, B.A., Sutton, G.G., et al. 2002. Heterochromatic sequences in a Drosophila whole-genome shotgun assembly. Genome Biol. 3: RESEARCH0085.

Kaffer, C.R., Srivastava, M., Park, K.Y., Ives, E., Hsieh, S., Batlle, J., Grinberg, A., Huang, S.P., and Pfeifer, K. 2000. A transcriptional insulator at the imprinted H19/Igf2 locus. Genes \& Dev. 14: 1908-1919.

Kafri, T., Ariel, M., Brandeis, M., Shemer, R., Urven, L., McCarrey, J., Cedar, H., and Razin, A. 1992. Developmental pattern of gene-specific DNA methylation in the mouse embryo and germ line. Genes \& Dev. 6: 705-714.

Kanduri, C., Pant, V., Loukinov, D., Pugacheva, E., Qi, C.F., Wolffe, A., Ohlsson, R., and Lobanenkov, V.V. 2000. Functional association of CTCF with the insulator upstream of the $\mathrm{H} 19$ gene is parent of origin-specific and methylationsensitive. Curr. Biol. 10: 853-856.

Kaneda, M., Okano, M., Hata, K., Sado, T., Tsujimoto, N., Li, E., and Sasaki, H. 2004. Essential role for de novo DNA methyltransferase Dnmt3a in paternal and maternal imprinting. Nature 429: 900-903.

Lam, W.W., Hatada, I., Ohishi, S., Mukai, T., Joyce, J.A., Cole, T.R., Donnai, D., Reik, W., Schofield, P.N., and Maher, E.R. 1999. Analysis of germline CDKN1C (p57KIP2) mutations in familial and sporadic Beckwith-Wiedemann syndrome (BWS) provides a novel genotype-phenotype correlation. $J$. Med. Genet. 36: 518-523.

Leighton, P.A., Ingram, R.S., Eggenschwiler, J., Efstratiadis, A., and Tilghman, S.M. 1995. Disruption of imprinting caused by deletion of the $H 19$ gene region in mice. Nature 375: 34-39.

Lewis, A., Mitsuya, K., Umlauf, D., Smith, P., Dean, W., Walter, J., Higgins, M., Feil, R., and Reik, W. 2004. Imprinting on distal chromosome 7 in the placenta involves repressive histone methylation independent of DNA methylation. Nat. Genet. 36: 1291-1295.

Li, E., Beard, C., and Jaenisch, R. 1993. The role of DNA methylation in genomic imprinting. Nature 366: 362-365.

Lin, S.P., Youngson, N., Takada, S., Seitz, H., Reik, W., Paulsen, M., Cavaille, J., and Ferguson-Smith, A.C. 2003. Asymmetric regulation of imprinting on the maternal and paternal chromosomes at the Dlk1-Gt12 imprinted cluster on mouse chromosome 12. Nat. Genet. 35: 97-102.

Mager, J., Montgomery, N.D., de Villena, F.P., and Magnuson, T. 2003. Genome imprinting regulated by the mouse Polycomb group protein Eed. Nat. Genet. 33: 502-507.

Maher, E.R. and Reik, W. 2000. Beckwith-Wiedemann syndrome: Imprinting in clusters revisited. J. Clin. Invest. 105: 247-252.

Mancini, D.N., Rodenhiser, D.I., Ainsworth, P.J., O'Malley, F.P., Singh, S.M., Xing, W., and Archer, T.K. 1998. CpG methylation within the $5^{\prime}$ regulatory region of the BRCA1 gene is tumor specific and includes a putative CREB binding site. Oncogene 16: 1161-1169.

Mancini-DiNardo, D., Steele, S.J.S., Ingram, R.S., and Tilghman, S.M. 2003. A differentially methylated region within the gene Kcnq1 functions as an imprinted promoter and silencer. Hum. Mol. Genet. 12: 283-294.

Matzke, M.A. and Birchler, J.A. 2005. RNAi-mediated pathways in the nucleus. Nat. Rev. Genet. 6: 24-35.

McGrath, J. and Solter, D. 1984. Inability of mouse blastomere nuclei transferred to enucleated zygotes to support development in vitro. Science 226: 1317-1319.

Nielsen, S.J., Schneider, R., Bauer, U.M., Bannister, A.J., Morrison, A., O'Carroll, D., Firestein, R., Cleary, M., Jenuwein, T., Herrera, R.E., et al. 2001. Rb targets histone $\mathrm{H} 3$ methylation and HP1 to promoters. Nature 412: 561-565.

Ogawa, Y. and Lee, J.T. 2002. Antisense regulation in X inactivation and autosomal imprinting. Cytogenet. Genome Res. 99: 59-65.

O'Keefe, D., Dao, D., Zhao, L., Sanderson, R., Warburton, D., Weiss, L., Anyane-Yeboa, K., and Tycko, B. 1997. Coding mutations in p57KIP2 are present in some cases of Beckwith-Wiedemann syndrome but are rare or absent in Wilms tumors. Am. J. Hum. Genet. 61: 295-303.

Paulsen, M., Khare, T., Burgard, C., Tierling, S., and Walter, J. 2005. Evolution of the Beckwith-Wiedemann syndrome region in vertebrates. Genome Res. 15: 146-153.

Reinhart, B., Elijanne, M., and Chaillet, J.R. 2002. Shared role for differentially methylated domains of imprinted genes. Mol. Cell. Biol. 22: 2089-2098.

Schoenherr, C.J., Levorse, J.M., and Tilghman, S.M. 2003. CTCF maintains differential methylation at the Igf2/H19 locus. Nat. Genet. 33: 66-69.

Sleutels, F., Zwart, R., and Barlow, D.P. 2002. The non-coding Air RNA is required for silencing autosomal imprinted genes. Nature 415: 810-813.

Smilinich, N.J., Day, C.D., Fitzpatrick, G.V., Caldwell, G.M., Lossie, A.C., Cooper, P.R., Smallwood, A.C., Joyce, J.A., Schofield, P.N., Reik, W., et al. 1999. A maternally methylated CpG island in KvLQT1 is associated with an antisense paternal transcript and loss of imprinting in BeckwithWiedemann syndrome. Proc. Nat1. Acad. Sci. 96: 8064-8069.

Stoger, R., Kubicka, P., Liu, C.-G., Kafri, T., Razin, A., Cedar, H., 
Mancini-DiNardo et al.

and Barlow, D.P. 1993. Maternal-specific methylation of the imprinted mouse Igf2r locus identifies the expressed locus as carrying the imprinting signal. Cell 73: 61-71.

Surani, M.A.H., Barton, S.C., and Norris, M.L. 1984. Development of reconstituted mouse eggs suggests imprinting of the genome during gametogenesis. Nature 308: 548-550.

Tanaka, M., Puchyr, M., Gertsenstein, M., Harpal, K., Jaenisch, R., Rossant, J., and Nagy, A. 1999. Parental origin-specific expression of Mash2 is established at the time of implantation with its imprinting mechanism highly resistant to genome-wide demethylation. Mech. Dev. 87: 129-142.

Thakur, N., Kanduri, M., Holmgren, C., Mukhopadhyay, R., and Kanduri, C. 2003. Bidirectional silencing and DNA methylation-sensitive methylation-spreading properties of the Kcnq1 imprinting control region map to the same regions. J. Biol. Chem. 278: 9514-9519.

Thakur, N., Tiwari, V.K., Thomassin, H., Pandey, R.R., Kanduri, M., Gondor, A., Grange, T., Ohlsson, R., and Kanduri, C. 2004. An antisense RNA regulates the bidirectional silencing property of the Kcnq1 imprinting control region. Mol. Cell. Biol. 24: 7855-7862.

Thorvaldson, J.L., Duran, K.L., and Bartolomei, M.S. 1998. Deletion of the $\mathrm{H} 19$ differentially methylated domain results in loss of imprinted expression of H19 and Igf2. Genes \& Dev. 12: 3693-3702.

Tremblay, K.D., Saam, J.R., Ingram, R.S., Tilghman, S.M., and Bartolomei, M.S. 1995. A paternal-specific methylation imprint marks the alleles of the mouse $H 19$ gene. Nat. Genet. 9: 407-413.

Umlauf, D., Goto, Y., Cao, R., Cerqueira, F., Wagschal, A., Zhang, Y., and Feil, R. 2004. Imprinting along the Kcnq1 domain on mouse chromosome 7 involves repressive histone methylation and recruitment of Polycomb group complexes. Nat. Genet. 36: 1296-1300.

Wang, L., Brown, J.L., Cao, R., Zhang, Y., Kassis, J.A., and Jones, R.S. 2004. Hierarchical recruitment of polycomb group silencing complexes. Mol. Cell 14: 637-646.

Wutz, A., Smrzka, O.W., Schweifer, N., Schellander, K., Wagner, E.F., and Barlow, D.P. 1997. Imprinted expression of the Igf2r gene depends on an intronic CpG island. Nature 389: 745-749.

Wutz, A., Rasmussen, T.P., and Jaenisch, R. 2002. Chromosomal silencing and localization are mediated by different domains of Xist RNA. Nat. Genet. 30: 167-174.

Yan, Y., Frisén, J., Lee, M.-H., Massagué, J., and Barbacid, M. 1997. Ablation of the CDK inhibitor p57KIP2 results in increased apoptosis and delayed differentiation during mouse development. Genes \& Dev. 11: 973-983.

Yatsuki, H., Joh, K., Higashimoto, K., Soejima, H., Arai, Y., Wang, Y., Hatada, I., Obata, Y., Morisaki, H., Zhang, Z., et al. 2002. Domain regulation of imprinting cluster in Kip2/Lit1 subdomain on mouse chromosome 7F4/F5: Large-scale DNA methylation analysis reveals that DMR-Lit1 is a putative imprinting control region. Genome Res. 12: 1860-1870.

Yoon, B.J., Herman, H., Sikora, A., Smith, L.T., Plass, C., and Soloway, P.D. 2002. Regulation of DNA methylation of Rasgrf1. Nat. Genet. 30: 92-96.

Zhang, P., Liégeois, N.J., Wong, C., Finegold, M., Hou, H., Thompson, J.C., Silverman, A., Harper, J.W., DePinho, R.A., and Elledge, S.J. 1997. Altered cell differentiation and proliferation in mice lacking p57KIP2 indicates a role in Beckwith-Wiedemann sydrome. Nature 387: 151-158. 


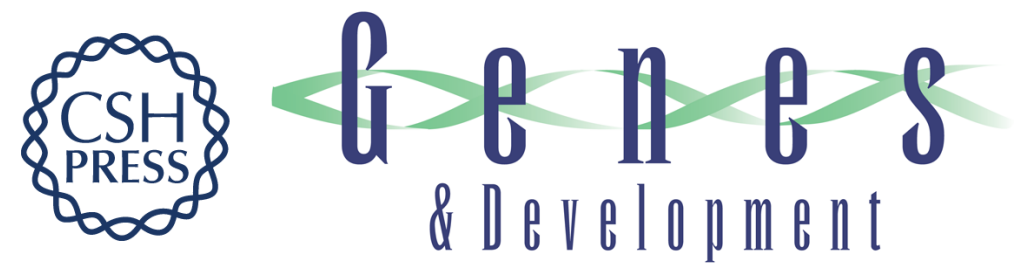

\section{Elongation of the Kcnq1ot1 transcript is required for genomic imprinting of neighboring genes}

Debora Mancini-DiNardo, Scott J.S. Steele, John M. Levorse, et al.

Genes Dev. 2006, 20:

Access the most recent version at doi:10.1101/gad.1416906

\section{Related Content Imprinting mechanismsit only takes two \\ Florian M. Pauler and Denise P. Barlow \\ Genes Dev. May , 2006 20: 1203-1206 \\ References This article cites 58 articles, 14 of which can be accessed free at: \\ http://genesdev.cshlp.org/content/20/10/1268.full.html\#ref-list-1 \\ Articles cited in: \\ http://genesdev.cshlp.org/content/20/10/1268.full.html\#related-urls \\ License
Email Alerting Receive free email alerts when new articles cite this article - sign up in the box at the top Service right corner of the article or click here.

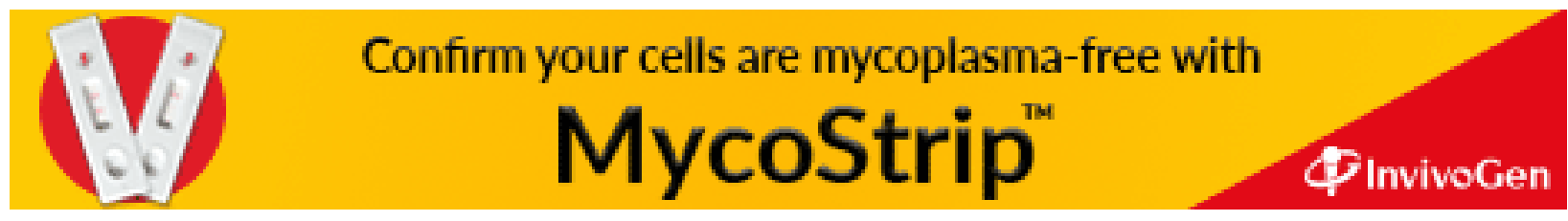

